\title{
The Gaze of Icon
}

\section{The Eye Worship in Primitive Belief and Its Expressions in Plastic Arts}

\author{
Weiduo Wang \\ School of Art \\ Soochow University \\ Jiangsu, China 215000 \\ School of art and design \\ China University of Mining and Technology \\ Jiangsu, China 210002
}

\begin{abstract}
Eyes are important sensory organs of human body. The primitive belief believes that the opening and closing of eyes divide light and darkness, and further connect with life and death, so in ancient mythology system it is regarded as the eyes of sun and gods, it is seen as the channel of soul, and even can communicate with heaven, earth, Gods and people. This knowledge affects the practice of ancient plastic arts, and in some civilized systems - such as the ancient Shu culture represented by Sichuan Guanghan Sanxingdui site in China, the worship of eyes is particularly clear and profound. Almost all of the icons in the belief systems acquire vitality by depicting the eyes, and they use their gaze to proclaim power and make preach, to discipline and create the worshipers who worship them.
\end{abstract}

Keywords - eyes; gaze; primitive beliefs; myth; plastic arts

\section{INTRODUCTION}

We often say that the eyes are "window of the soul", "Qiaoxiaoqianxi, Meimupanxi (smile is so beautiful, and eyes are full of expectation)", people never begrudge ink for the description of eyes since ancient times. The eyes are the important organs for us to explore and perceive the objective world. The acquisition of outside information is mostly realized by visual communication. Gaze is one of the most important means of communication and expression among the vast majority of mammals including mankind, and it has great significance in the fields of biology and sociology. The behavior of mutual gaze implied explore, alert, concern, identity, fear, demonstrations, intimidation, and other information, if you have the experience to make eye contact with a wild beast or raise a dog or cat pets, you will find this behavior is a silent language can cross the species. Human beings can express their complex emotions and feelings through the cooperation between the eyebrows and eyes.

Ancient people has noticed the special magic power of eyes an gaze very early, in the primitive beliefs and mythology system, the eye has its special status: the opening and closing of eyes can divide light and dark, so the ancients linked it to the sun worship; the opening and closing of eyes also related to life and death, so it is regarded as the channel of soul; and the rich information conveyed by gaze has been given a mysterious color in original thinking. Eyes and their gaze behavior has become the sacred symbol in many cultural systems, also it is an important theme which the ancient plastic arts deliberately expressed. In the process of creation, eye has always been deliberately emphasized: on one hand, it will be exaggerated art treatment, on the other hand with the similar reason of finishing touch, the production of many religious icons always depicts the eyes at last-it is soul given moment, after " open the eyes", the icon seems to have a life.

\section{SUN IS THE EYE OF GODS}

Myth is the integration and evidence of primitive beliefs, it largely reflects the face of original thinking. In the eyes of the ancient ancestors, eyes can bring light, just as the role of the sun, and thus they put some of the sun godhead into the eyes, and the sun is the eyes of gods. In Nordic mythology, the image of Hodur, the god of darkness, is a blind man in order to distinguish with his twin brother who has bright blue eyes-the god of light Balder. In Madagascar's mythology system, sun is the eye of the god Maso-Andro - similar myths are common in the Indian and South Pacific cultures. For example, Maori in New Zealand believe that the god Mawoi hanging his eyes in the sky to become the sun. This simple and clear thinking has global universality: the eye of Horus, one of the most important holy symbols of ancient Egypt, is the one that can see everything. It can give the living power and wisdom, but also to protect the boat of dead souls arrived to the deep soil on the other side - it is actually the embodiment of the sun. In the Aryan mythology, sun is the eyes of the ancient Iranian god Mitra, the eyes of god Varuna and Agni, which is why from Hesiodos to Macrobius they all say sun is the eyes of Zeus (Jupiter). Ancient Germanic people called sun the eyes of their main god Wuotan, and one eye of Nordic main god Odin also is the sun. In the eyes of Zoroastrians, Ahura Mazda's eyes are the sun and the moon, just as the Arctic Samoyed people consider the sun and the moon as the eyes of heaven. The goddess Moerae, the famous goddess of Greek mythology, shares and conveys the eye of the sun, which does not represent light, but represents the time flow of the past, present and future - but equally significant.

The thinking of considering the sun as the eye of the gods was also written in many of our mythology. As known to preserve the most complete and detailed myth information, 
"Shan Hai Jing" has the description of Zhu Long the god of Zhongshan:

The god of Zhongshan, called the Zhu Yin, when he open his eyes it is daytime, when he closed his yes it is nighttime; when he blows it is winter, when he exhale it is summer; he does not drink, eat, and he does not have breath. Once he blow a breath, it will create wind; his body is thousand miles long, he has human face, snake body, whole body in red color, lived under Zhongshan.

\section{"Shan Hai Jing · Hai Wai Bei Jing"}

\section{And it also said:}

Outside the Northwest Sea, at the north of Chishui, there is a Zhangwei mountain. There is a God on the mountain with human face snake body and the whole body is in red color. When he closes his eyes it is nighttime, when he open his eyes it is daytime. He does not eat, sleep or rest. His food is wind and rain, he can light the darkness so it was called Zhu Long.

\section{"Shan Hai Jing .Da Huang Bei jing"}

"Shan Hai Jing," has many mistakes, and "Da Huang Jing" was a little early than "Shan Hai Jing", so what Guo Pu note Zhu Yin is confirmed as Zhu Long. Open eyes is daytime, close eyes is nighttime, so Zhu Long's eyes are undoubtedly the sun. In Northern Europe the similar mythologyv ersion can be found and all of them are showing the icy chill north soil atmosphere.

$\mathrm{Xu}$ Zheng from Three Kingdom period wrote in his "Wu Yun Li Nian Ji":

The first born man is Pangu, after he dead his body changed: his breath became wind and cloud, his sound became thunder. His left eye became the sun, his right eye became the moon, his four legs and arms and five body parts became the four pole and five great mountains. His blood became rivers...

"Jiang Shi"

After the death of the open god, his body, skin and hair became the things of the world, this plot exist in many myths (especially in South Asia and West Asia). There are many similar descriptions in the oral literature of minority nationalities in southwest China, except that $\mathrm{Pan} G \mathrm{Gu}$ is changed to goddess (Lahu epic "Mupa Mipa"), Tigers (Yi oral literature "Meige") and Holy cow (Hani epic "Ao se mi se"), etc. "Wu Yun Li Nian Ji" also said:

Pangu has dragon head and snake body, his blows is wind and rain, his exhale is thunder, he open his eyes is daytime, he close his eyes is nighttime. After he dead his bone became mountains and forests, his body became rivers and seas, his blood became Huai river, his hair became grass and wood.

\section{"Guang Bo Wu Zhi”}

Here, Pangu was again given the godhead of Zhu Long, eyes open and close can divide day and night. North and South myth model achieved the combination. In fact, in Zhuang, Li, Shui, Maonan, Mulao and other Zhuang Dong language national language, eyes and sun have the same word root.

\section{Multi-EYES, ONE-EYE AND ThREE-EYES GodS}

Since the eyes are so special, then the emergence of multieyes god is a natural. The Vedic god of war, Indra, is called "god of thousand eyes". In Greek mythology also has the description about the giant hundred-eye Argus. He was insightful, he even could insight changes of a grass and a leaf, after he dead his hundred eyes turned into the "pseudo-eye" on the tail of peacock. In addition to the multi-eyes gods, one-eye giant man' images are also common in myths, the most famous of which is the son of Poseidon in "Odyssey", cannibal Polyphemus. In fact, the legend of one-eye giant was spread all over the Eurasian steppe and the Balkans, the origin of which is based on primitive belief of ancient Turkic ethnic from the Yenisei River Basin and Altai Mountains. In the Kazakh epic "Bassat" and the Kirghiz epic "Manas" all have the plot of oneeye giant. Mountain-like giant overlooking the sky with one eye, he can communicate with God. In "Shan Hai Jing. Hai Wai Bei Jing,"there is a description of the "one-eye country"; in "Da Huang Bei Jing" it also said"there is a person with one eye on the center of his face. Someone said his surname is Wei, and he is the son of Shaohao, and he eats millet." Two northern myths referred should be the same thing, and associated with one-eye giant in the original belief of the Altai region.

Three-eye worship has many remains in the Central Asian civilizations, it is one of the common gods which ancient IndoEuropean believed. Persia Zoroastrianism, India Brahmanism and so all dedicated three-eye god. This third eye is the source of the mysterious power, with has the power that the normal eyes do not have. In some of the descriptions, the main god of Zoroastrianism, Ahura Mazda has an extra eye between his eyebrows; Shiva, one of the three main gods of Hinduism, the god of destruction and creation, and his companion Parvati are both three-eyes gods. The third eye of Shiva can emit fire to destroy the enemy, which is actually still the conversion of sun worship. Some scholars say, there are many elements from India in Chu culture. "Chu Ci. Zhao Hun" said:

Tubo is nine feet tall with sharp horns; he has thick back with blood finger, chase people very fast like horse; he has three eyes and tiger head, with a cow body. The three-eye Tubo jusst fit the image of Shiva. Shiva beliefs do spread widely, such as wind god of Zoroastrianism Veshparkar in the western region of Sogdian people, his artistic image is from Shiva.While the latter according to the record is the model of Erlang Shenjun in Chinese Ming and Qing Dynasties tales of mystery and supernatural - in addition to three eyes, they both holding a Trident. Under the influence of Aryan tradition and Brahmanism, Buddhism give full play to the worship of "the third eye", and call it "sky eye". The Buddhist sutra emphasizes that "sky eye" must require an excellent wisdom root, the practitioner may have infinite supernatural powers which so-called "sky eye power". Buddha statues are often Urna-Laksana, as one of the thirty-two images of Tathagata. Buddhist sutra said:

Shizun has Baihao between eyebrows, like sun in the sky, it can shining with light, called "Baihao Image". "Buddhist Scriptures. Liao Jie Pin Di Jiu"

This shining baihao "like sun in the sky", which has the same function with sky eye. Buddhism Tantric icon born with 
three eyes is very common. The study of Tibetan Buddhism plastic arts, up from the Bodhisattva down to demons, Most of the angry image of Qiyi Xiba and Dejiba two categories of Dharma(the Dharma of the god, including the various Ming Wang, Tian Wang, Gui Wang, auspicious Tian Nv and Babu Guizhong) are three eyes, which just fit the regulation of "Zangjing. Zaoxiang Liangdu Jing": "face-type man is square and woman is round, three eyes wide open, red and round. Two eyebrows are frown". One of Gusnyin Bodhisattva's incarnations Baidumu was born with seven eyes - one pair for each feet and hands, three on the face - for mercy shines use.

\section{WORSHIP OF EYES-EYES IN ANCIENT PlASTIC ARTS}

In the primitive beliefs and mythical systems of different civilizations, the eyes generally have extraordinary status and mysterious significance, and from the prehistoric plastic arts, works which highlighting the specificity of eyes have been emerging and too numerous to mention. Such as the European Aurignacian began to appear prehistoric rock paintings and bone sculptures, they made more efforts to depict the animal's eyes. Another example is the nomadic burial gold and silver fabric eye protection device, which began from more than 3,000 years since the beginning of $\mathrm{BC}$ in the two rivers region and has continued until now - Stein (A. Stein) called it "the goggles". The burial custom spread to Central Asia and the Near East areas, and across the Eurasian steppes affected the national customs of Finno-Ugric language family. Use precious metal to cover the dead people's eyes may be derived from the thinking of the eyes are the pathways of people's soul.

The eye is of particular importance for hunters who travel between hills. Prehistoric rock paintings distributed in the mountainous areas of northern China and the eastern coastal areas also have many works that focus on the eyes. Such as The human face status rock painting series in general cliff at south of Jinping Mountain in Lianyungang city, the faces are round and square, the widely open eyes are particularly eyecatching. The human face status which also highlight the eyes are generally appeared in the rock painting group in Helan Mountain, Yinshan, Langshan, Zhuozi mountain Kucai ditch, Shao Shao ditch and other places. Hongshan culture unearthed a rich number of $\mathrm{Yu}$ zhulong (also known as $\mathrm{Yu}$ shoujue in order to distinguish it from the C-shaped Yulong), or it can be called bear, I believe that is more like an embryo of mimicry to describe the early developed head and the huge eye tissue which not open yet with realistic hand-written, contains protect fertility and reproduction this simple and mysterious witchcraft demand of simulation witchcraft and sympathetic witchcraft for the tribal growth, human prosperity is the root. The Niu Heliang Hongshan goddess pottery head sculpture unearthed in 1983 and belongs to the late Hongshan culture type, especially use green Xiuyan jade for the bright eyes. Goddess eyes wide open, eyebrows erect, looks angry claimed her power with no doubt, her momentum of dignity can not be disobedient, so that viewers couldn't watch her for a long time. The same period Sumerian civilization Uruk goddess statue, face looks peaceful like water, deep mystery through the empty eyes (also may have a gem filled with huge eye socket), as if passed the information from the ancient, it is also solemn with extraordinary quality-Two goddess' eyes both can see through human mind.

Longshan culture jade often decorated with deformed human face pattern, the human face pattern on unearthed jade adze, jade axe, jade knife from Shandong Rizhao two town sites has a whirlpool-like huge circular eyes. Liangzhu jade wares at the same period such as jade-cong and jade axe also have the similar human face pattern. The most prominent feature of this kind human face pattern is the wide open circular eyes. The jade-cong unearthed from Yuhang County Fan Shan Liangzhu tomb has huge holes at both four corners, as if you can spy the world. This is certainly not the general human face but can be called "God face pattern". They must have a more ancient archetype in terms of the degree of sophistication and formality that they characterize. This pattern was inherited by the Yin Shang bronzes and then formed the so called animal face pattern" with rich changes and lawful to follow - Song "Xuan He Bo Gu Lu" called it "Taotie pattern". Some people think that the Yin Shang culture is malicious and insidious, ferocious and heartless, they cast ferocious beast face on the bronze in order to frighten slaves. While the bronze ritual vessels and utensils are placed on the ancestral temple or palace, the aristocracy is still rare to see let alone a slave? If they can not see, fright will be impossible. In fact, the animal face is God's face, that is, the Yin Shang ancestor God mentioned by Vasilyev ("The origin of Chinese civilization"). "Zhu ding xiang wu, bai wu er wei zhi bei", casting the face of ancestor gods with dignity face and torch eyes and gods from other countries on the tripod, on one hand it could make the gods enjoy all the sacrifices; on the other hand it could frighten demons, protect the people, ensure the country will last forever, "children and grandchildren could enjoy the happy". Wang Sunman explained the reasons why Yu made the tripod Jiuding:

... So that the people know god and demon. So the people into the mountains and rivers without fear. All the demons will not harm them. So the whole country will have the blessing from gods."

\section{"Zuo Zhuan· The Third Year of Xuan Gong Period"}

In fact, it also fits on the Yin Shang bronze.

\section{The GAZE OF ICON-ANCIENT SHU CIVILIZATION SANXINGDUI RUINS}

On a worldwide scale, there is no ancient culture with the most prominent eye worship and most distinctive and fascinating better than ancient Shu culture which represented by Sichuan Guanghan Sanxingdui ruins. Among the thousands of pieces of bronze, gold, jade devices unearthed from Sanxingdui, the most distinctive piece should be the bronze head sculpture, standing sculpture, mask and eye-shaped devices. Its age almost the same with Yin Shang period, but the shape and purport are different from Central Plains region, its characteristics are obvious and very mysterious.

The most representative bronzes include bronze vertical eyes mask with a width of $138 \mathrm{~cm}$, number K2(2): 148. It has square face, blade eyebrow, eagle nose, dagger-type big ear with lotus front and decorated with goulian pattern; thin lip with wide mouth, mouth corner up with a mysterious smile on 
the face; between the eyebrows ,the two sphenoid bones and the end bottom of two mandibles all have square shaped holes for install other components. The most impressive is the eyes of the mask, a huge cylindrical pupil protruding unexpectedly about $16 \mathrm{~cm}$, the gaze like torch out of the eye socket. The entire line of the mask is smooth and clever, with elegant and succinct outline, large volume, solemn majesty, quite a sense of religious ritual. From modern concept, from the mysterious reveals surrealistic meaning and a strong visual shock. Another similar shape but slightly smaller bronze vertical eye mask with crown, number K2(2): 142, between the eyebrows casting hook cloud ornament about $70 \mathrm{~cm}$ high, called Kuilong or Bird, it should be the same thing as "She" called by Hayashi Minao on the Shang Dynasty bronze beast pattern, it seems to indicate the word "Xin" which means godship in oracle inscriptions. It has strange modeling, magnificent style, so amazing. When these bronze masks unearthed they all have color painting traces.

The unearthed four bronze head sculptures with gold mask also are eye-catching. The head sculpture is divided into two types dome and flat, each type has two pieces, both showed a long cylindrical shape, the bottom of the neck like a pen tip, vertical eyebrow with vertical eyes, exaggerated olive-shaped eyes prominent from the middle ridge. Gold mask use the extension gold skin and adhere with bronze sculpture with lacquer and lime. The mask covered from forehead to chin, and then covered the ears, ear lobe has holes, and the eyebrow was hollow. Bronze makes the gold mask even more brilliant bright, the overall noble dignity with extraordinary quality. There are dozens of diamond-shaped, hook-shaped eye-shaped bronze devices with large size, the length can reach more than half a meter. In the center of Eye-shaped device pupil are circular projection, at four corners there are holes for installation fix.

Sanxingdui ruins are large sacrificial pits, these unearthed cultural relics should be the ancestral temple treasures of the ancient Shu royal family. Bronze portrait and mask are the worship and sacrifice icons of ancient Shu people. Ancient Shu people not only casting statues which highlighted the eyes, but also casting a large number of independent eye-shaped devices, this indicates that they have a firm and distinctive eye worship practices. This phenomenon which developed eye worship to such degree is very rare in ancient civilizations. In addition to the eye bring light like the sun and people linked it to life and death, which make them emerged a special awe, there must be other reasons for the original beliefs. Such exaggerated artistic performance attracted different opinions: some scholars have investigated a large number of bird-shaped objects unearthed from Sanxingdui ruins, they attributed the eye focus to the ancient Shu people's birds worship customs, and linked it to the Dongyi ethnic migration; someone based on the bronze sacred tree which unearthed at the same time, believe that the eyes highlighted statues are related with the "Zhi mu zheng cheng" god of Zhu Long (see above) and the sun worship; and more people think that the statues are actually the original god of ancient Shu people that is mentioned in the "Hua Yang Guo Zhi. Shu Zhi" written by Chang Qu from the Eastern Jin Dynasty. It described" the eyes are vertical, and he are the original king", he educated people engaged in farming and sericulture, and then they believe the bird-shaped devices are related with the legend second generation ancestor of ancient Shu people "Yu Fu". Analysis of Oracle there are about 20 ways to write the word "Shu", most of the ways have a large oblique eye for the upper part- very much like the ministerial pattern of bronze objects, the lower part is curled body. They called themselves Shu, this should be closely related to Chan chong legend and the portraits and masks unearthed from Sanxingdui ruins. In fact, the sun worship theory, bird totem worship theory and ancestors worship theory could all be integrated throughout. In the early days of China, especially in the Dongyi and the southern ethnic cultural systems, sun and bird have the same godhead so they can be seen as one thing, and they can both be associated with the worship of eyes. As eyes were given a supernatural power, then later emerged the legend of god Chan chong with vertical eyes, and erected its icon status to be commemorated. In other words, after entering the patriarchal clan period, the ancestors (heroes) worship objects Chan chong and Yu Fu replaced the sun-god bird totem worship from matriarchal clan period (in the prehistoric belief system the sun was mostly negative). "Father" knocked "Old grandmother" off the altar, and retain some beliefs, this theocratic change phenomenon is universal. Sun, bird, eyes, Chan Chong who has magic vertical eyes, country named "Shu", all these are the symbols in the ancient Shu people's belief system, which are indispensable for the same meaning. They just make continuously inherit progressive and mutual integration along with the development of civilization.

\section{CONCLUSION}

Eyes are so important, in the plastic arts naturally need to be emphasized. Today's portraits are still reflected that. It is through the eyes, we distinguish the quiet and mysterious Mona Lisa, paranoid Van Gogh, remorse Ivan Ledi, deep and delicate Tolstoy, unruly Mussorgsky their own characters, temperaments and mental states. In the ancient icon shaping process, the treatment of eyes is extremely sacred and cautious. In some ancient traditions, even in order to avoid pagan injury and deliberately ignore the eyes. Of course, exaggerated artistic performance still accounted for the majority. From the artistic creation act itself, the works we described and shaped are our view and watch object. This kind of viewing or gaze with the will of power gives the viewer a sense of superiority over the work. But the production of icon can reverse this mechanism: when the icons are erected, they get the "life" through the final step of opening the eyes, and the person who makes it becomes the gaze object. This is what B.A.Uspensky says: "An internal viewer in the fantasy world is staring at an outside audience". The eyes of the icons look directly in front, majesty or compassion, as if they can snoop the performance of each viewer and through every believer's heart. Even if you avoid the eye contact with icon, you can also feel a kind of "imagination gaze". As David Freedberg put it in "The Power of Images": "The icon views will continually find themselves controlled by the eyes of the icon", and then lodged on the ground and prostrate themselves in worship. It can be said that the gaze of icon eyes discipline and create the believers. So you can see that the eyes are the soul of icon, icon need to make their magic through their eyes. It is no wonder that when Prophet Mohammed removes the Islamic gods in Krall white 
temple, he destroyed their eyes first. And in Islamization period, some Buddhist statues in Xinjiang Kizilga also got their eyes destroyed by the Muslim blade.

\section{REFERENCES}

[1] Mao Dun. Myth Research [M]. Tianjin: Baihua Literature and Art Publishing Company, 1981.

[2] Edward Taylor (Translated by Lian Shusheng). Primitive culture [M]. Guilin: Guangxi Normal University Press, 2005.

[3] Gao Fujin. Sun Worship and Sun Myth [M]. Shanghai: Shanghai People 's Publishing Company, 2002.

[4] Yuan Ke. Collating and annotating of Shan Hai Jing [M]. Beijing: Beijing Union Publishing Company, 2014.

[5] Helmut Wu Lixi (translated by Li Xuetao). Buddha explanation [M]. Beijing: Social Science Literature Publishing Company, 2010.

[6] Ye Xingsheng. Tibetan mask art [M]. Chongqing: Chongqing Publishing Company, 1992.

[7] Gao Huo. European Prehistoric Art [M]. Shijiazhuang: Hebei Education Press, 2003.

[8] Song Yaoliang. China 's prehistoric god face rock paintings [M]. Shanghai: Sanlian Bookstore Shanghai Branch, 1992.

[9] Zhao Xianzhang, Zhu Cunming. Art Archeology and Art Aesthetics [M] Shanghai: Shanghai University Press, 2008.

[10] Hayashi Minao(Translated by Chang Yaohua and others). The Pattern of God and the Beast [M]. Beijing: SDX Joint Publishing Company, 2009.

[11] Wu Hong. Art in Etiquette[M]. Beijing: SDX Joint Publishing Company. 2005 